\title{
Burning out? Watch your own incivility and the emotions you spread
}

\author{
Laura Petitta $^{\mathrm{a}, *}$ and Lixin Jiang ${ }^{\mathrm{b}}$ \\ ${ }^{a}$ Sapienza University of Rome, Rome, Italy \\ ${ }^{\mathrm{b}}$ University of Auckland, Auckland, New Zealand
}

Received 11 November 2018

Accepted 8 August 2019

\begin{abstract}
.
BACKGROUND: The present study focuses on perpetrators of workplace incivility.

OBJECTIVE: We set to answer two questions: 1) why the perpetrator instigates uncivil behaviors in the workplace, and 2) what are the consequences of workplace incivility on the perpetrator him/herself.

METHODS: We examined the perpetrator burnout outcome of instigated incivility and infected emotional contagion as predictor of one's uncivil behaviors towards others and tested the cross-country structural invariance of the hypothesized nomological network on data from the U.S. and Italy.

RESULTS: Data from employees in the U.S. $(N=350)$ and Italy $(N=273)$ suggest that contagion of joy infected into others and anger infected into others were related to instigated incivility, which, in turn, was positively related to emotional exhaustion and cynicism. Our results were structurally invariant across the two countries.

CONCLUSIONS: Similar to the victims of incivility, the perpetrator of workplace incivility also suffers from heightened burnout. As such, an employee experiencing and infecting into other employees his/her own negative/positive emotions increases/decreases his/her own tendency to initiate rude behaviors toward others. Overall, our findings shed light on predictors and consequences of workplace instigated incivility. We hope our research can serve as a springboard to the understanding and prevention of incivility initiated by employees.
\end{abstract}

Keywords: Instigated incivility, burnout, emotional contagion infected, cross-country

\section{Introduction}

Workplace incivility can be defined as "lowintensity deviant behavior with ambiguous intent to harm the target, in violation of workplace norms for mutual respect. Uncivil behaviors are characteristically rude and discourteous, displaying a lack of regard for others" ([1] p. 457). Unfortunately, workplace incivility is an ongoing concern as reports of personal infringements are on the rise [2]. Indeed, according to an American nationwide survey, Americans encounter incivility more than twice a day and

*Address for correspondence: Laura Petitta, Department of Psychology, Sapienza University of Rome, Via dei Marsi, 78, 00185, Rome, Italy. Tel.: +390649917641; E-mail: laura.petitta@ uniroma1.it.
70 percent of respondents believe that incivility has reached crisis proportions [3]. Because of its prevalence, it is crucial to deepening our understanding of workplace incivility.

Understandably, most workplace incivility research has focused on the negative impacts of workplace incivility on victims. This focus is warranted given that the victims of workplace incivility suffer from greater psychological distress $[4,5]$, burnout $[6]$, and other negative consequences $[7,8]$. However, we argue that in order to truly prevent workplace incivility, it is equally, if not more, important to investigate why the perpetrator instigates incivility and what are the consequences of instigated incivility on the perpetrators themselves. Thus, to respond to Schilpzand et al.'s [7] call and 
contribute to the workplace incivility literature, this study takes the perspective of employees who are instigators (i.e., initiators) of workplace incivility [1] and explores the predictors as well as outcomes of instigated workplace incivility. Overall, the current paper sought to examine whether the emotions experienced and spread towards others by an employee (i.e., emotional contagion infected) impact the same employee's tendency to behave uncivilly with other employees (i.e., instigated incivility), which in turn contributes to the rise of his/her own levels of job burnout (see Fig. 1 for nomological structure).

In the sections below, we first present an overview of the theoretical foundations of workplace incivility in general and instigated incivility in particular. Next, we briefly define job burnout and delineate arguments regarding the relationship between incivility and burnout. We then present the theoretical background for emotional contagion and, in particular, the overlooked perspective of emotional contagion infected. Finally, we test our hypotheses on the relationship between emotional contagion infected, instigated incivility, and burnout using a cross-country sample of 350 employees in the U.S. and 273 employees in Italy.

\section{Workplace incivility and job burnout}

Workplace incivility is defined as deviant behavior violating workplace norms for mutual respect [1]. It is a form of misconduct at work that is less intense (i.e., low-intensity deviant behavior) in comparison to active, direct, and intentional aggressive or violent behavior. Hence, instigated incivility at work can be defined as the extent to which an individual initiates rude and uncivil actions towards other employees
[9]. The initiators of workplace incivility typically engage in sarcasm, disparaging tones and remarks, making demeaning and rude comments about someone both privately and publicly, spreading rumors about colleagues, withholding information, doubting the abilities of capable employees, speaking loudly outside of a coworker's office while the coworker attempts to work, reading emails on one's cell phone while in a meeting, and hostile stares [4, 10-12].

While the offensive impact of such thoughtless, disregarding, and inconsiderate behavior may be unintended, it reflects the perpetrator's lack of awareness of others and neglected effort to consider the impact of one's own actions on others. An additional distinguishing and subtle characteristic of incivility is that the intent to harm is considered to be ambiguous because it is difficult for the instigator/the target/the observers to know whether the act of the instigator was voluntary or ignorance/oversight. Even if the instigator may have the intention to harm the target, yet he/she may not even realize such intent. Because of the non-transparent aggressive nature of uncivil acts, it is easy for the instigator to deny such acts and instead attribute it to the misinterpretation and/or hypersensitivity of the target [1].

The consequences of instigating workplace incivility need to be examined. One of the most fundamental human needs is the need for affiliation [13]. It has been shown that people who lack positive relationships exhibit a variety of ill effects (e.g., [14, 15]). Thus, displaying uncivil conducts and failure to satisfy the need for affiliation may have devastating consequences such as increased job burnout.

Job burnout is a psychological syndrome resulting from a prolonged exposure to interpersonal and social stressors at work [16]. Burnout represents a process of psychological erosion and a cumula-

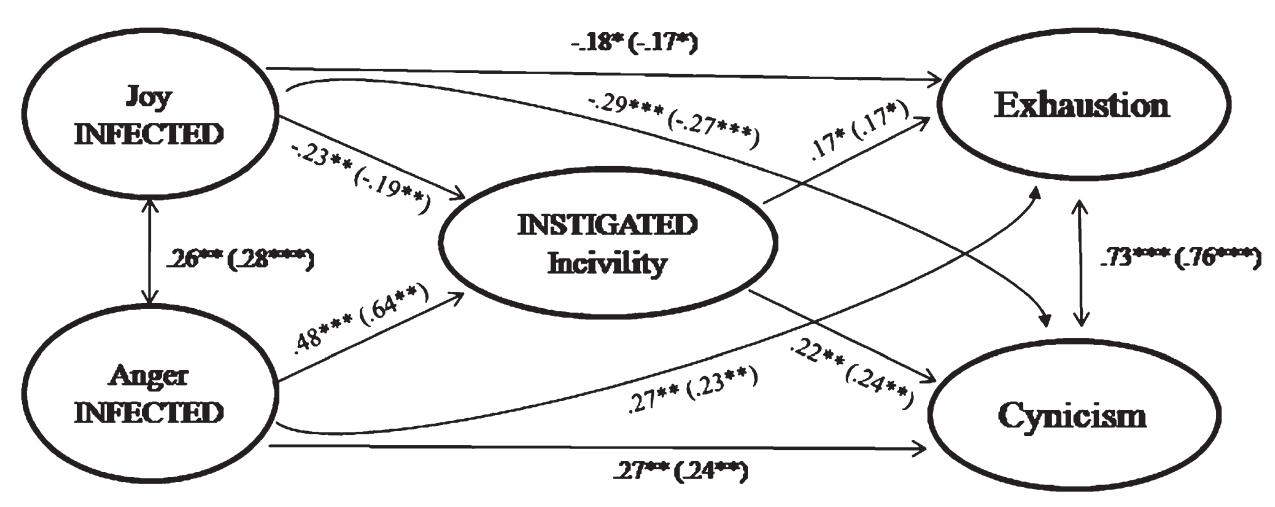

Fig. 1. Standardized structural coefficients for the final structural model for the U.S.A. and Italy (in parentheses). 
tive stress reaction to ongoing occupational stressors that tends to be fairly stable over time. Maslach and Leiter's [17] most recent contribution describes burnout as the manifestation of emotional exhaustion and cynicism. Emotional exhaustion is defined as emotional and physical depletion associated with a lack of energy to face work situations. The exhaustion component represents the basic individual strain dimension of burnout and is often the first warning sign that people are feeling overextended by work demands, drained and used up, and without any source of replenishment and recovery [6]. While emotional exhaustion embodies the depletion of emotional and physical resources, cynicism represents the interpersonal context dimension of burnout and refers to a negative, callous, or excessively detached response to various aspects of one's job and distance oneself emotionally and cognitively from one's work. As such, cynicism captures the critical aspects of the relationships people have with their work and represents the interpersonal component of burnout [18]. Over time, workers who self-protect from the overload of interpersonal strain also tend to develop a negative reaction to people and to the job, and shift towards detachment from their work and the workplace. The combined emotional exhaustion and cynicism components of burnout place the individual strain experience within the social, interpersonal context of the workplace [16].

We propose that instigating workplace incivility may increase one's burnout because the act of incivility disrupts the possibility of affiliation, one of the most fundamental human needs, [13], and damages the interpersonal cooperative relationships [19]. Dysfunctional relationships among organizational members link to heightened burnout [20]. For example, poor relational transactions in the workplace (e.g., interpersonal conflict, a lack of mutual support) result in burnout $[6,18]$. Furthermore, the anger literature [21] suggests that higher levels of anger expression (e.g., harmful behaviors of instigated incivility) increase one's stress and decrease one's well-being. Pertinent to our investigation is the argument $[22,23]$ that anger expression (e.g., instigated incivility) causes the perpetrator to appear as a threat to others around, thus leading to emotional distress and poorer social functioning and interactions (e.g., cynicism) for the perpetrator. Indeed, Leiter and colleagues [24] provided initial evidence that incivility initiated by an employee was positively related to his/her own levels of emotional exhaustion and cynicism. We therefore argue that instigated incivility is costly to the perpetrator him/herself in terms of their burnout. Specifically, we propose that:

Hypothesis 1: Instigated incivility is positively related to one's own emotional exhaustion (1a) and cynicism (1b).

\section{Emotional contagion infected: An overlooked perspective}

Emotional contagion is the nonconscious process through which humans automatically signal and detect emotions as sensory information (e.g., sound, sight, touch) and attune to other people's expression of emotions, thus being able to emotionally converge [25]. People tend to mimic the facial, vocal, postural, and behavioral emotional cues "of those around them, and thereby "catch" others' emotions as a consequence of such facial, vocal, and postural feedback" ([26] p.3). Thus, it refers to an individual experience of emotion that includes the interpersonal component of the feelings exchanged during social encounters [26]. The simultaneous detection and reflection of the emotional cues of others occurs below conscious recognition and is enabled by the Mirror Neuron System mimicking the brain activation pattern underlying an emotional stimulus [2, 28]. Although emotional contagion is activated involuntarily and automatically, the neocortex receives the emotional signal milliseconds thereafter thus enabling the conscious awareness of one's emotional exchanges with others [29].

Noteworthy, the mirror neuron system underpins the mechanisms through which people (a) perceive others' expression of emotions and (b) send emotional signals that arouse emotions in others during social interactions [27, 30]. In other words, an individual absorbs emotions expressed by other people with whom they interact (emotional contagion absorbed), but the same individual also "infects" others around with one's own emotions that s/he feels and communicates (emotional contagion infected) through various means [31]. Despite theory [32] and neuroscience evidence [27] showing that people are able to draw others into their emotional orbits and infect them with the emotions they express (i.e., contagion infected), emotional contagion research tends to overlook the impact of emotional contagion infected (i.e., individuals virally spreading their own emotions into others). For example, the empirical investigation on dyadic situations, wherein one individual(s) is a receiver of emotions and another 
individual(s) is the sender of emotions, usually conceptualizes and measures emotional contagion only from the perspective of the emotions absorbed by others. Hence, research is needed to better understand how the contagion of one's own emotions transmitted to others during social encounters contribute to social transactions.

Thus, we purposely focus on emotional contagion infected into others. Specifically, we engage a conceptualization of emotional contagion that focuses on the transmission of specific and discrete basic emotions (i.e., joy, anger), as proposed by Doherty [33], rather than investigating an individual's general tendency to spread a wide variety of affective clues, such as emotions, feelings, and moods [31]. Below we present arguments on the link among emotional contagion infected, burnout, and instigated incivility, and develop hypotheses of their interrelationship.

\subsection{Emotional contagion infected and job burnout}

As noted above, burnout is a psychological syndrome characterized by an adverse emotional (i.e., exhaustion) and relational (i.e., cynicism) reaction to work-related stressors, making employees to feel emotionally drained, worn out, and resourceless [18]. Previous research has documented that emotional contagion is a predictor of burnout. For example, consistent with the Job Demands-Resource (JD-R) model of work-related stress [34], a study by Petitta, Jiang, and Härtel [35] found that contagion of anger absorbed from others may serve as a job demand that is related to increased job burnout, whereas contagion of joy may serve as a job resource that is related to reduced burnout. Indeed, contagion of a positive emotion (i.e., joy) may facilitate social bonding, cooperation, and synchronization of opportunities [36]. Conversely, contagion of a negative emotion (i.e., anger) may require sustained effort to counteract relational strain and deplete psychological resources [37]. Thus, previous research has demonstrated emotional contagion of joy and anger predicts employee burnout.

Yet, this above evidence refers to emotional contagion absorbed by others whereas the current study focuses on the contagion of joy and anger experienced by an employee and infected into others around (i.e., emotional contagion infected). While no study has previously investigated the link between emotional contagion infected and burnout, we argue that an employee experiencing joy and spreading (i.e., infecting) joy among fellow employees similarly contribute to the development of a supportive and constructive environment which, in turn, prevents him/her from burning out. On the contrary, employees feeling angry and virally infecting other people with anger likely contribute to social conflict, miscommunication, and a lack of consideration in the workplace, thus prompting the rise of burnout levels. Indeed, meta-analytic findings suggest that the expression (e.g., contagion infected into others) of positive emotion (e.g., joy) is related to better social outcomes and well-being (e.g., decreased burnout), while the expression (e.g., contagion infected into others) of negative emotion (e.g., anger) is associated with dysfunctional social interactions and poorer wellbeing (e.g., increased burnout; [22]). Consistent with the above arguments, we hypothesize that:

Hypotheses 2: Emotional contagion of joy infected into others directly and negatively predicts exhaustion (2a) and cynicism (2b).

Hypotheses 3: Emotional contagion of anger infected into others directly and positively predicts exhaustion (3a) and cynicism (3b).

\subsection{Emotional contagion infected, instigated incivility, and burnout}

The emotion literature [22] provides meta-analytic evidence that positive (e.g., joy) vs. negative emotions (e.g., anger) lead to the development of healthy/dysfunctional social functioning (e.g., instigated incivility), which in turn is crucial in maintaining overall health and well-being (e.g., burnout). Building upon this emotional processessocial behavior-strain link [22], below we develop our arguments on the relationship among infected emotional contagion, instigated incivility, and job burnout contextualized in the work setting.

Emotional contagion at work is best described as the unintentional tendency of people to exchange emotions with one another (i.e., both absorbed from and infected into others) during social interactions, thereby achieving an emotional convergence that spreads in large organizational communities [26, 32]. Hence, emotional contagion epidemically circulates during socialization processes that allow the exchange of emotions among actors. We note that social processes underlying the dynamic of emotional contagion are also inherent in the concept of workplace incivility [1], understood as a set of rude, disgraceful, and low-intensity deviant behaviors 
that employees enact while interacting with others at work. Indeed, Johnson and Indvik [38] suggest that employees who observe incivility among coworkers may model that behavior and initiate an incivility spiral with another employee, thus reiterating a pattern of distrust, disrespect, and dissatisfaction on the job that becomes "contagious" organization wide. As Leiter et al. noted, "a central construct in incivility research is that not only are acts of incivility damaging for the victim, they are contagious as well; they can spread throughout organizations, affecting both targets and non-targets ([10] p. 116)."

Furthermore, experiencing negative emotions at work appears to be a key factor in prompting a spiral of reciprocal and accelerating mistreatment within the workplace, both received and instigated [39]. Hence, as a contagious social stressor, incivility is also induced by employee emotion-related dynamics. Specifically, according to the stressor-emotion model [40], when employees hold negative emotions and then experience a stressor at work [41], these conditions may trigger their engagement in uncivil behaviors. Perhaps when a stressor is perceived as unfair (e.g., others' disregard and rudeness), employees likely attempt to restore justice in their work environment [10]. However, it is often the case that when stressors cause an employee to feel anger and frustration, his/her attempt to restore justice will manifest itself as revengeful, uncivil acts (whether intentional or not). As a result, one's negative state and uncivil actions may turn the overall work environment into one that is predominately negative. Anger, in particular, has been demonstrated to be a powerful antecedent of incivility $[1,10]$ because employees who experience anger are more likely to feel frustration and enact aggressive behavioral responses [42].

On the other hand, positive social interactions have been shown to prevent uncivil behavior [6]. According to the "broaden and build" model [43], collegiality experiences that create opportunities for recognition and social support provide access to positive resources at work, thus broadening employees' perspective and allowing them to build on opportunities that they tend to overlook when experiencing stress. By extension, and complementing the stressor-emotion model above, positive emotions (e.g., joy) may prevent the deterioration of interpersonal relations and social environment and therefore are negatively related to incivility.

Taken together, our arguments provide an overarching framework for developing a model incor- porating antecedents and consequences of instigated incivility from the perspective of the employee as the perpetrator. Our overarching prediction is rooted into (a) a model including the contagion of positive and negative emotions infected into others as conjoint predictors of instigated incivility and burnout, (b) a stressor-emotion model predicting that anger infected may be positively associated with instigated incivility, which in turn is associated with a greater experience of work-related strain reactions (i.e., burnout), and (c) the "broaden and build" model predicting that joy infected may be negatively related to instigated incivility, which in turn is related to decreased burnout. Together, we expect that an employee contagion of both positive and negative emotions infected into others (i.e., emotional contagion infected) serves as emotional and relational strain that affects his/her likelihood of developing work stress reactions, both directly as well as indirectly via instigated incivility toward others. Based on the above arguments, we expect that:

Hypothesis 4: Emotional contagion of joy infected into others negatively predicts exhaustion [4a] and cynicism [4b], both directly and indirectly via instigated incivility.

Hypothesis 5: Emotional contagion of anger infected into others positively predicts exhaustion (5a) and cynicism (5b), both directly and indirectly via instigated incivility.

\section{The current study}

Taken together, this study has three main aims, each contributing to the extant literature in a unique way. The first aim was to provide an empirical examination of the consequences of instigated workplace incivility on the perpetrator him/herself (as opposed to the victim, the focus of the extant workplace incivility literature). While conventional wisdom and common sense suggest that releasing anger by displaying aggressive behaviors may 'blow off some steam' and therefore reduce one's own stress and burnout, the current paper argues that instigated incivility is costly to the perpetrator him/herself in that instigated incivility threatening the need for affiliation [13] and the benefits associated with social relationships [19, 44] might increase, rather than decrease, one's burnout. In doing so, we challenge conventional wisdom and common sense and contribute to the workplace incivility literature by 
purposely focusing on an underexplored area-the perpetrator consequences of workplace incivility.

The second aim was to understand why the perpetrator engages in workplace uncivil behaviors. In doing so, we rely on the literature on emotional contagion $[25,45]$ and explore the contagion of emotions (i.e., anger, joy) infected by the perpetrator into other individuals around them as the predictors of instigated incivility. In the current study, we investigate whether the contagion of emotions that an individual experience and epidemically infects into others with whom s/he interacts at work (i.e., contagion infected) is associated with the likelihood of displaying workplace uncivil behaviors. Understanding the emotion-related antecedents of instigated incivility is important because it would allow us to educate perpetrators and develop effective interventions targeting workplace incivility.

The third aim was to provide an integrated examination of the experiences of instigated workplace incivility (see Fig. 1) with employee participants from both the U.S. and Italy. That is, we test whether instigated incivility would serve as the mediator between one's emotions virally spread on others on the one hand and one's burnout levels on the other in two different national contexts (i.e., U.S., Italy) in order to paint a complete picture of instigated incivility, enhance the conceptual replication of our hypotheses, and increase the generalizability of our findings.

\section{Method}

\subsection{Participants and procedure}

In order to test our hypotheses, data were gathered from employees located in the U.S. and Italy. The reason for conducting a cross-country examination was twofold. From a methodological perspective, we wanted to verify that our results were not context dependent (i.e., to determine if they would generalize to a different cultural context). Moreover, according to Eurofound [46], to date Italy is the only one of two countries in the European Union to have classified job burnout as an occupational disease, thus demonstrating how concerns regarding work-related stress are becoming increasingly prevalent. As such, there were practical reasons as well for the collection of Italian data.

U.S. Sample. An online anonymous survey was administered to 367 employees in the United States while 350 participants provided completed data on key study variables. The final sample demographics were as follows: $63.5 \%$ of respondents were female; they were 35.99 years old on average $(S D=11.90)$; the majority worked full-time (84.2\%) and held a permanent job (94.5\%); and about half participants were employee $(58 \%)$ while another half held a position of supervisor, manager, and executive (42\%). After providing participants with informed consent materials that explained the anonymous nature of the data collection and their rights as research participants, employees completed the on-line survey containing the research measures through Amazon Mechanical Turk (Mturk), an online crowdsourcing website. Previous research has demonstrated that data collected via Mturk has psychometric properties similar to data collected using other convenience sampling methods [47].

Italian Sample. Paper and pencil surveys were administered in person to 273 participants in Italy. The final sample demographics were as follows: $69.6 \%$ of respondents were female; they were 30.73 years old on average $(S D=10.28)$; the majority worked full-time (79.2\%), held a permanent job (71.2\%), and held an employee position (86.7\%). Members of the research team provided participants with informed consent materials that explained the anonymous nature of the data collection and their rights as research participants and distributed the questionnaire. In order to assure confidentiality, employees were allowed to complete the survey at home and return it in a sealed envelope to the research team.

\subsection{Measures}

The U.S. and Italian versions of the survey contained the scales described below and were worded in English and Italian, respectively. Furthermore, for the Italian versions of job burnout measure, we used the previously validated Italian translation. We translated Italian version of emotional contagion infected into English and English version of instigated incivility into Italian. We used the standard translation-backtranslation procedure recommended by Brislin [48]. The correspondence of the original and the backtranslated items was then verified by the authors.

\subsubsection{Emotional contagion infected}

Emotional contagion of emotions infected into others by the respondent (i.e., emotional contagion 
infected) was measured by the Emotional Contagion at Work Scale (ECWS [45]). Previous findings support the empirical distinctiveness of infected contagion of the two discrete basic emotions assessed in this research, namely, joy and anger [45]. Higher scores of "joy infected" and "anger infected" reflect greater infection to others with one's experienced emotions. The ECWS assessed emotional contagion by presenting respondents with items that represent different work-situated emotional experiences. A sample item from the 3-item joy-infected subscale was, "When I am happy, those around me are also more content", and a sample item from the 3-item anger-infected subscale was, "When I use an aggressive tone, I feel that those around me tend to become angry". Participants were asked to answer how frequently the emotional situation is experienced using a 5-point Likert scale ranging from 1 (Never) to 5 (Always).

\subsubsection{Instigated incivility}

Instigated incivility was assessed using five items of the Straightforward Incivility Scale [49], targeting the self as a source of incivility. Respondents were asked to indicate the frequency that they spoke or behaved rudely to other people at work. Items were rated on a 7-point Likert scale ranging from 0 (never) to 6 (daily). A sample item was "You spoke rudely to someone."

\subsubsection{Job burnout}

The Italian version [50] of the Maslach Burnout Inventory-General Survey (MBI-GS [51]) was used, including five items measuring exhaustion and six items assessing cynicism. A sample exhaustion item was "I feel emotionally drained from my work" and a sample cynicism item was "I doubt the significance of my work". Items were rated on a 7-point frequency scale ranging from never (0) to daily (6).

\section{Results}

The means, standard deviations, reliability estimates (coefficient alpha), and zero-order correlations among the study variables were presented in Table 1.

\subsection{Goodness of fit for the U.S. sample and the Italian sample}

Prior to testing our hypotheses, we examined the goodness-of-fit values of the CFA models separately for the U.S. sample and the Italian sample. To maximize the reliability and parsimony of our analyses, we created item-parcels for construct measures with more than three items. We followed the recommendation by Little, Cunningham, Shahar, and Widaman [52] and created three item-parcels per construct by sequentially assigning items per parcel based on the highest to lowest item-to-construct correlations. Subsequent confirmatory factor analyses using Mplus 7.0 [53] provided support for the discriminant validity of the scales used. Specifically, the goodness-to-fit values for the U.S. sample were $\chi^{2}(80)=109.17$, RMSEA $=0.045$, $\mathrm{CFI}=0.984$, SRMR $=0.042$, showing an excellent fit. Similarly, the Italian sample also displays good fit indices $\left(\chi^{2}(80)=143.50\right.$, RMSEA $=0.076$, $\mathrm{CFI}=0.938, \mathrm{SRMR}=0.067)$.

\subsection{Measurement invariance across the U.S. sample and the Italian sample}

Table 2 shows the results of analyses for measurement invariance. Because of the excessive Type I error rate associated with the chi-square difference test in large samples, we evaluated the relative fit of constrained models instead using change in CFI, with differences of .01 or less demonstrating equivalent fit [54]. Each of the four invariance models provided good fit, and the decrease in the CFI value was less

Table 1

Descriptive statistics, correlations, and reliabilities

\begin{tabular}{lccccccc}
\hline & $M$ & $S D$ & $\alpha$ & 1 & 2 & 3 & 4 \\
\hline 1. Joy-infected & $3.42(3.03)$ & $0.90(0.84)$ & $0.77(0.71)$ & $0.33^{* *}$ & 0.00 & 0.03 & -0.05 \\
2. Anger-infected & $2.50(2.64)$ & $0.94(0.82)$ & $0.78(0.66)$ & $0.27^{* *}$ & $0.39^{* *}$ & $0.16^{* *}$ & $0.23^{* *}$ \\
3. Instigated incivility & $2.03(2.59)$ & $1.11(1.31)$ & $0.93(0.93)$ & -0.07 & $0.26^{* *}$ & $0.34^{* *}$ & $0.37^{* *}$ \\
4. Exhaustion & $3.54(2.03)$ & $1.74(1.25)$ & $0.95(0.88)$ & $-0.11^{*}$ & $0.26^{* *}$ & $0.23^{* *}$ & $0.57^{* *}$ \\
5. Cynicism & $3.29(1.76)$ & $1.77(1.32)$ & $0.92(0.85)$ & $-0.20^{* *}$ & $0.23^{* *}$ & $0.29^{* *}$ & $0.74^{* *}$ \\
\hline
\end{tabular}

Note. ${ }^{*} p<0.05,{ }^{* *} p<0.001$. Mean and SD for Italian data are in parenthesis; correlations below the diagonal are for the U.S. sample and correlations above the diagonal are for the Italian sample. 
Table 2

Results of tests for measurement and structural invariance across U.S. and Italy

\begin{tabular}{|c|c|c|c|c|c|c|c|}
\hline \multirow[b]{2}{*}{ Models(M) } & \multicolumn{5}{|c|}{ Model Fit } & \multicolumn{2}{|c|}{ Model Difference } \\
\hline & $\chi^{2}$ & $d f$ & RMSEA & CFI & SRMR & $\Delta \mathrm{M}$ & $\Delta \mathrm{CFI}$ \\
\hline $\mathrm{CFA}_{\text {USA }}$ & 109.17 & 80 & 0.045 & 0.984 & 0.042 & - & - \\
\hline CFA $_{\text {ITA }}$ & 143.50 & 80 & 0.076 & 0.938 & 0.067 & - & - \\
\hline M1: Configural & 229.76 & 160 & 0.052 & 0.970 & 0.054 & - & - \\
\hline M2: Metric & 246.13 & 170 & 0.053 & 0.967 & 0.060 & M2-M1 & -0.003 \\
\hline M3: Scalar & 260.21 & 180 & 0.053 & 0.965 & 0.061 & M3-M2 & -0.002 \\
\hline M4: Residual & 297.03 & 195 & 0.057 & 0.956 & 0.067 & M4-M3 & -0.009 \\
\hline S5: Structural Model for U.S. & 109.17 & 80 & 0.045 & 0.984 & 0.042 & - & - \\
\hline S6: Structural Model for Italy & 143.50 & 80 & 0.076 & 0.938 & 0.067 & - & - \\
\hline S7: Unconstrained Structural Model across groups & 339.087 & 195 & 0.068 & 0.950 & 0.067 & - & - \\
\hline S8: Constrained Structural Model across groups & 369.804 & 205 & 0.071 & 0.943 & 0.102 & S7-S8 & -0.007 \\
\hline
\end{tabular}

Note. At each step in the sequence of invariance tests, all earlier constraints remain in place. RMSEA = robust root-mean-square error of approximation; $\mathrm{CFI}=$ robust comparative fit index; $\mathrm{SRMR}=$ robust standardized root means square residual .

than .01 for each invariance comparison. Therefore, there was adequate evidence for the quality of form, loadings, intercepts, and residuals across the U.S. sample and the Italian sample.

\subsection{Multi-group structural equation models}

In the first step, we examined separately the goodness-of-fit values for the structural equation models for the U.S. and Italian data. As shown in Table 2, the values for both the U.S. (model S5) $\left[\chi^{2}(80)=109.17, \quad\right.$ RMSEA $=0.045 \quad(0.020-0.064)$, $\mathrm{CFI}=0.984, \mathrm{SRMR}=0.042]$ and Italy (model S6) $\left[\chi^{2}(80)=143.50, \quad R M S E A=0.076(0.056-0.096)\right.$, $\mathrm{CFI}=0.938$, SRMR $=0.067]$ model showed good fit to the data. Results from the subsequent comparison of single analysis across both the U.S. and Italian data without any constraints (model S7 in Table 2) and with constrained imposed (model S8) showed that there was not a significant decrement in model fit, thus supporting an invariant pattern of relationships among variables across the U.S. and Italy. The final best fitting model is presented in Fig. 1.

As can be seen, instigated incivility was positively related to both emotional exhaustion (respectively, $0.17, p<0.05$, for both the U.S. and Italy) and cynicism (respectively, 0.22, $p<0.01$, for the U.S., and $0.24, p<0.01$, for Italy). Furthermore, joy-infected was negatively related to both emotional exhaustion (respectively, $-0.18, p<0.05$, for the U.S., and -0.17 , $p<0.05$, for Italy) and cynicism (respectively, -0.29 , $p<0.001$, for the U.S., and $-0.27, p<0.001$, for Italy) while anger-infected was positively related to both emotional exhaustion (respectively, $0.27, p<0.01$, for the U.S., and $0.23, p<0.01$, for Italy) and cynicism (respectively, 0.27, $p<0.01$, for the U.S., and 0.24, $p<0.01$, for Italy). Hence, Hypotheses 1,2 , and 3 were all supported.

Meanwhile, joy-infected was negatively related to instigated incivility (respectively, $-0.23, p<0.01$, for the U.S., and $-0.19, p<0.01$, for Italy) while angerinfected was positively related to instigated incivility (respectively, 0.48, $p<0.01$, for the U.S., and 0.64, $p<0.01$, for Italy). Finally, when considering indirect effects, emotional contagion of joy-infected exerted a negative indirect effect on both exhaustion (respectively, $-0.04, p<0.05$, for the U.S., and $-0.03, p<0.05$, for Italy) and cynicism (respectively, $-0.05, p<0.05$, for the U.S., and $-0.05, p<0.05$, for Italy) via instigated incivility. Emotional contagion of anger-infected exerted a positive effect on both exhaustion (respectively, $0.08, p<0.05$, for the U.S., and $0.07, p<0.05$, for Italy) and cynicism (respectively, $0.11, p<0.01$, for the U.S., and $0.10, p<0.01$, for Italy) via instigated incivility. Thus, we found support for Hypotheses 4 and 5 that instigated incivility mediated the relation between joy-infected, as well as anger-infected, with emotional exhaustion and cynicism. Overall, the model explained the 22\% of instigated incivility variance in the U.S. and $14 \%$ in Italy, the $15 \%$ of exhaustion variance in the U.S. and $11 \%$ in Italy, and the $22 \%$ of cynicism variance in the U.S. and $19 \%$ in Italy.

\section{Discussion}

Inconsiderate and uncivil interactions among employees are the enemy of collaborative work transactions that are detrimental to organizations, including substantial direct (e.g., production loss, replacing employees that have quit) and indirect 
(e.g., company reputation) costs. Indeed, Porath and Pearson [2] report an estimated annual cost of experiencing incivility at $\$ 14,000$ per employee. Conversely, norms concerning how people ought to behave in professional settings are the keys to create a socially positive and productive environment [55]. Therefore, promoting a civil workplace environment that minimizes workplace incivility and prevents employees from feeling miserable in the job and developing adverse consequences are important for both employees and their organization.

Taking the perspective of the employee as perpetrator or initiator, the present study examined a model of antecedents and consequences of instigated incivility. Building on the JD-R model of etiology of burnout incorporating the contagion of positive/negative emotions infected into others as job resources/demands $[34,35]$, a stressor-emotion model [40], and the "broaden and build" model [45], we tested a crosscountry model of employee instigated incivility as a mediator linking the contagion of one's own positive (joy) and negative (anger) emotions infected into others and one's burnout.

The results of the study were consistent with our hypotheses. Our findings showed that instigated incivility was positively related to both one's own levels of emotional exhaustion and cynicism, which was in line with previous research on burnout as an outcome of incivility (e.g., [10]). Thus, with previous research findings on incivility victims, we can conclude that also the perpetrator of workplace incivility suffers from burnout consequences as a result of the uncivil social encounter. As such, the dysfunctional interaction of workplace incivility is a "lose-lose" situation where nobody "wins".

We further explore why employees engage in uncivil behaviors in the workplace. We found that contagion of joy infected into others (i.e., joy-infected) and anger infected into others (angerinfected) was related to instigated incivility. Noteworthy, the effect of anger contagion was twice as strong as joy infected. This highlights the importance of considering not only the commonly studied emotional contagion absorbed from others, but also the contagion of emotions infected into others when understanding instigated incivility.

Moreover, joy-infected and anger-infected predicted (respectively, negatively and positively) emotional exhaustion and cynicism both directly and indirectly via instigated incivility. When employees experienced anger that they infected into others around, they were not only prompted to enact more rude behaviors toward others, but they also tended to report higher feelings of being emotionally drained (emotional exhaustion) and engaged in distancing strategies from their work and the workplace (cynicism). The opposite occurred when an employee experienced and infected joy into others around. That is, the epidemic spreading of a positive emotion (i.e., joy) prevented the occurrence of rude behaviors which, in turn, also prevented employees from burning out. Notably, these results are consistent (i.e., invariant) across different national contexts (i.e., U.S. and Italy).

\subsection{Theoretical implications}

Our cross-country findings on the predictors (i.e., emotions infected into others at work) and consequences (i.e., emotional exhaustion, cynicism) of employee instigated incivility make several novel contributions. Most notably, we advance the extant literatures of workplace incivility, burnout, and emotional contagion by examining our conceptual model from the initiator perspective. That is, we take the standpoint of the employee who initiates emotional contagion (i.e., feels an emotion and infects it into others around) and subsequently displays (or refrains from initiating) uncivil behaviors which, in turn, result in higher (or lower) levels of burnout. Thus, we complement the most common approach in the research of the three key constructs (i.e., emotional contagion, incivility, burnout) that relies on the dyadic framework of the perpetrator vs. target dynamic for incivility, or sender vs. receiver dynamic for contagion and burnout. To clarify, we use a figureground analogy. Common dyadic approach usually places both the perpetrator and the target in the "figure" position and the others around in the "ground" position in their community with whom they relate, thus representing the social context. Unlike this traditional approach, the employee as perpetrator in our study is the sole actor in the "figure" position, while others around populate the "ground" as the social context. Hence, the employee is the protagonist in acting emotional contagion infected, initiating incivility and causing his/her own burnout. In doing so, we contribute to the existing research on incivility by investigating antecedents and consequences of the less studied instigated incivility. While our approach takes the perspective of the incivility initiator and focuses on the mediation model of contagion of emotions $\rightarrow$ incivility $\rightarrow$ reported burnout, this set of experiences is not merely a personal problem. 
Consistent with Maslach and Leiter's [6] approach to workplace well-being, we argue that incivility and burnout are developed in response to problematic relationships between employees and their workplaces, and therefore social and organizational issues.

An additional unique contribution is the balanced approach to the emotion-related processes underpinning incivility by simultaneously considering positive (i.e., joy-infected) and negative (i.e., anger-infected) emotional exchanges as predictors of displaying constructive or destructive behaviors as well as positive or negative outcomes for individuals [56]. Given that empirical investigation of (e.g., [57]) and literature reviews on (e.g., [10]) incivility are skewed towards focusing on negative emotions (anger in particular) as antecedents of uncivil actions at work, we contribute to the ongoing research by examining the role of positive emotions (i.e., joy) besides negative emotions. Our findings suggest that consistently across two different national contexts, the effect of anger-infected on instigated incivility is twice as strong as joy-infected. As such, whether American or Italian, an employee's own anger spread towards others may take precedence over their happiness experienced at work in prompting the initiation of rude behaviors towards other employees.

Our study also extends previous theorizing about emotional contagion by incorporating emotional contagion infected as a predictor of incivility and burnout. Indeed, this is the first study to empirically investigate emotional contagion infected as a predictor of instigated incivility and work strain reaction. Our findings suggest that an employee's anger vs. joy transmitted to other employees decreases/increases the tendency to treat others with courtesy, regard, and appreciation. As such, our findings also expand the JD-R model of the etiology of burnout [34], the stressor-emotion approach [40], and the "broaden and build" model [43]. While previous research [38] demonstrated that absorbed positive (i.e., joy) and negative emotions (i.e., anger) may respectively serve as a job resource and demand in predicting job burnout, our results further expand this framework by demonstrating contagion virally infected towards others as a job resource/demand in developing/preventing uncivil behaviors and burnout. Hence, including emotional contagion infected allows us to reveal how employees' own emotions set the tone for meaningful and respectful social interactions that foster well-being.

\subsection{Practical implications}

Workplace incivility is a disruptive behavior that interferes significantly with cooperation and partnership on the job and thus generates adverse outcomes for professional practice on multiple counts, ranging from unhealthy or hostile work environment that raises employee dissatisfaction to work errors and malpractice costs. As such, it is the organization's responsibility to specify workplace polices on desired standards of behavior. That is, organizations should not only state zero tolerance for incivility but also delineate guidelines to support victims who need to confront perpetrators and also help perpetrators to manage their work life more effectively [58]. According to Aquino and Thau [59], the two most consistent and strong predictors of mistreatment at work are the lack of clear guidelines for collegial behaviors and authoritarian leadership styles at the management level. Therefore, top management should take responsibility to set standards and code of conduct aimed at eliminating disruptive, uncivil behaviors in the workplace. For example, in order to build a civil workplace, the American Association of Critical Care Nurses [60] suggest the following six standards: authentic leadership, skilled communication, true collaboration, effective decision making, appropriate staffing that matches patient needs and competencies, and meaningful recognition.

More importantly, regardless of the perpetrators, top management and supervisors should address disrespectful behaviors and develop a culture of mutual respect. In line with this, Robbins and Judge [61] recommend the following practices to managers in order to create a positive organizational culture: (a) be a role model and be visible in order to exemplify the acceptable behavior in the workplace; (b) communicate expectations on standards of workplace conduct to reduce moral ambiguities; (c) offer training to reinforce the organization's standards of conduct, clarify acceptable practices, and address possible moral dilemmas; (d) visibly reward acts complainant with moral standards and punish unethical ones by including a point-by-point evaluation of a manager's decisions in measuring up against the organization's code of ethics; and (e) provide protective mechanisms, such as counselors or officers that provide employees with psychologically safe setting (e.g., without fear of reprimand) where they can discuss moral dilemmas or report deviant behavior. 
Moving further, our study demonstrated that instigated incivility is also a social problem that may be derived from emotion-related dynamics (emotional contagion infected) and has chronic costs for employees' well-being (emotional exhaustion and cynicism). As noted above, the ambiguous nature of instigated incivility (whether unintentional or intended) allows perpetrators to easily deny the harming nature of their rude action and its negative implications for their victims. Thus, we believe that our conceptual model, including the assessment of emotional contagion infected, can contribute to the efficacy of intervention programs. Specifically, Bowen, Privitera, and Bowie [62] suggest that an intervention strategy is more effective if it incorporates more elaborate insights of how incivility and violence arise from a combination of internal and external stressors. Their three-stage model proposes that the first step is to create a positive social environment through education on organization's policies and procedures to prevent issues of workplace mistreatment. The second stage is to teach employees about their emotions through several domains (e.g., social, neurological) in order to address any issues of workplace mistreatment as they occur. The third stage occurs when workplace mistreatment becomes an organizational-level crisis and includes various methods to counteract incivility with the involvement of the organization's human resources department.

The methodology used in our study can be useful here. The profiling results emerging from the infected contagion scale [45] and from the instigated incivility sub-scale of the Straightforward Incivility Scale (SIS [49]) would allow employees to gain awareness of their own contribution to emotional dynamics (i.e., contagion infected) in the workplace and how uncivil behaviors are prompted by one's own emotions that rise during social interactions. Of practical relevance for incivility interventions is the general framing of SIS incivility items [49] by asking the employees whether they have acted rudely or with disregard towards others rather than rate the frequency of a list of more specific behavior (e.g., [9]). While different units within an organization might carry different ways to enact incivility, the use of SIS may help map, compare, and intervene on incivility across different organizational departments. Furthermore, the measurement invariance of our scales across English and Italian contexts provide multinational companies and practitioners with valid assessment tools.
Building on an agentic perspective of individuals learning how to actively manage their social context [63], our conceptual model and accompanying scales would encourage a shift in employee mindset. Instead of solely focusing on the emotions that were injected to them by other individuals, employees may pay attention to the emotions that are firsthand experienced by themselves and then infected into others. Such an emphasis on one's own emotions ultimately allow one to explore the reasons why it emerges (e.g., frustration due to being impeded in one's desire or goal, trait based low self-control), thus helping oneself to recognize and understand how and why s/he may contribute to co-creating emotional ambience, which in turn prompts him/her to act rudely and disrespectfully as well as experience burnout. Ultimately, the awareness of emotion-spreading mechanisms should make it harder for instigators to deny their uncivil actions but easier to sustain voluntary change processes and develop more effective coping strategies dealing with emotional and relational stressors.

\subsection{Strengths, limitations, and future directions}

A notable strength of the current study is the twocountry data, which increase ecologic validity and generalizability of the research findings and applications. In particular, our study provides initial support for measurement equivalence of the English and Italian versions of the emotional contagion infected scale and instigated incivility assessed by SIS scale [49], thus paving the way for further investigation across different national contexts.

An arguable limitation is the cross-sectional selfreport nature of our data. Hence, the common method bias may threaten the validity of the findings. In particular, self-reports of emotional contagion perceptions used in this study may be affected by recognition and recall biases. To deal with these biases, future studies may rely on neuroscience experimental designs using thermal imaging and fMRI methods for measuring emotional contagion infected into others. Furthermore, while the cross-sectional nature of our data does not allow us to draw causal conclusions on the posited conceptual links, future longitudinal studies could provide added support for our model. For example, longitudinal research and experience sampling methodology could also better delineate the mediating role of incivility between emotional contagion and burnout. While both U.S. and Italian data were drawn from a wide variety of 
industry sectors, they were nonetheless convenience samples. Hence, our findings might be affected by the self-selection bias.

Although our hypotheses were fully supported, the current findings also warrant further investigation. Our study is an important first step at demonstrating why individuals engage in uncivil behaviors in the workplace and what are instigators' consequences of initiating incivility. Yet, this promising framework can be further advanced. An interesting venue for advancing our knowledge on the mechanisms through which emotion-related processes affect the emergence of incivility and work-related stress points at incorporating underexplored contextual factors, such as organizational culture and emotional climate [64]. Toward that end, future multilevel studies considering possible contextual differences may target employees nested within a large number and wide variety of teams and organizations.

\section{Conflict of interest}

None to report.

\section{References}

[1] Andersson LM, Pearson CM. Tit for tat? The spiraling effect of incivility in the workplace. Academy of Management Review. 1999;24:452-71.

[2] Porath CL, Pearson CM. The cost of bad behavior. Organizational Dynamics. 2010;39(1):64-71.

[3] Shandwick W, Tate P. Civility in America. http://www. webershandwick.com/uploads/news/files/Civility_in_Ameri ca_2013_Exec_Summary.pdf, 2013.

[4] Cortina LM, Magley VJ, Williams JH, Langhout RD. Incivility in the workplace: Incidence and impact. Journal of Occupational Health Psychology. 2001;6:64-80.

[5] Keashly L, Hunter S, Harvey S. Abusive interaction and role state stressors: Relative impact on student residence assistant stress and work attitudes. Work \& Stress. 1997;11:175-85.

[6] Maslach C, Leiter MP. New insights into burnout and health care: Strategies for improving civility and alleviating burnout. Medical Teacher. 2017;39(2):160-3.

[7] Schilpzand I, De Pater IE, Erez A. Workplace incivility: A review of the literature and agenda for future research. Journal of Organizational Behavior. 2016;37:S57-88.

[8] Sommovigo V, Setti I, Argentero P, O'Shea D. The impact of customer incivility and verbal aggression on service providers: A systematic review. Work. 2019;62(1):59-86.

[9] Blau G, Andersson LM. Testing a measure of instigated workplace incivility. Journal of Occupational and Organizational Psychology. 2005;78:595-614.

[10] Leiter MP, Peck E, Gumuchian S. Workplace incivility and its implications for well-being. Mistreatment in Organizations. 2015;1:107-35.
[11] Lim S, Cortina LM, Magley VJ. Personal and workgroup incivility: Impact on work and health outcomes. Journal of Applied Psychology. 2008;93(1):97-107.

[12] Pearson C, Porath C. The Costs of Bad Behavior: How Incivility Is Damaging Your Business and What to Do about It. New York: Penguin Books Ltd, 2009.

[13] Baumeister RF, Leary MR. The need to belong: Desire for interpersonal attachments as a fundamental human motivation. Psychological Bulletin. 1995;117(3):497-529.

[14] Leary MR, Kowalski RM. Impression management: A literature review and two-component model. Psychological Bulletin. 1990;107(1):34-47.

[15] Cacioppo JT, Hawkley LC, Berntson GG. The anatomy of loneliness. Current Directions in Psychological Science. 2003;12(3):71-4

[16] Maslach C. Job burnout: New directions in research and intervention. Current Directions in Psychological Science. 2003;12(5):189-192.

[17] Maslach C, Leiter MP. Early predictors of job burnout and engagement. Journal of Applied Psychology. 2008;93(3): 498-512.

[18] Maslach C, Leiter MP. Burnout. In G. Fink Ed., Handbook of Stress Series Volume 1, Stress: Concepts, Cognition, Emotion, and Behavior, London: UK, Elsevier, 2016, pp. 351-7.

[19] Nelson RJ. Biology of aggression. NY: Oxford University Press, 2006.

[20] Durand A-C, Bompard C, Sportiello J, Michelet P, Gentile S. Stress and burnout among professionals working in the emergency department in a French university hospital: Prevalence and associated factors. Work. 2019;63(1): 57-67.

[21] Diong SM, Bishop GD. Anger expression, copying styles, and well-being. Journal of Health Psychology. 1999;4(1): 81-96.

[22] Chervonsky E, Hunt C. Suppression and expression of emotion in social and interpersonal outcomes: A meta-analysis. Emotion. 2017;17(4):669-83.

[23] Lench HC, Tibbett TP, Bench SW. Exploring the toolkit of emotion: What do sadness and anger do for us? Social and Personality Psychology Compass. 2016;10:11-25.

[24] Leiter MP, Laschinger H, Day A, Oore D. The impact of civility interventions on employee social behavior, distress, and attitudes. Journal of Applied Psychology. 2011;96:1258-74.

[25] Hatfield E, Cacioppo JT, Rapson RL. Emotional contagion. Cambridge, UK: Cambridge University Press, 1994.

[26] Hatfield E, Cacioppo JT, Rapson RL. Emotional contagion. Current Directions in Psychological Science. 1993;2(3): 96-9.

[27] Iacoboni M. Imitation, empathy, and mirror neurons. Annual Review of Psychology. 2009;60(1):653-70.

[28] Rizzolatti G, Sinigaglia C. Mirrors in the brain: How our minds share actions and emotions. New York: Oxford University Press Inc, 2008.

[29] LeDoux J. Synaptic self: How our brains become who we are. Viking, NY, 2002.

[30] Nummenmaa L, Hirvonen J, Parkkola R, Hietanen JK. Is emotional contagion special? An fMRI study on neural systems for affective and cognitive empathy. NeuroImage. 2008;43:571-80.

[31] Hatfield E, Rapson RL. Emotional contagion and the communication of emotions. In M.T. Palmer, G.A. Barnett Ed., Progress in communication sciences Vol. 14, Stamford, CT: Ablex, 1998, pp. 73-89. 
[32] Hatfield E, Forbes M, Rapson RL. Marketing love and sex. Society 2012;49(6):506-11.

[33] Doherty RW. The Emotional Contagion Scale: A measure of individual differences. Journal of Nonverbal Behavior. 1997;21:131-54.

[34] Demerouti E, Bakker AB, Nachreiner F, Schaufeli WB. The job demands-resources model of burnout. Journal of Applied Psychology. 2001;86(3):499-512.

[35] Petitta L, Jiang L, Härtel CEJ. Emotional contagion and burnout among nurses and doctors: Do joy and anger from different sources of stakeholders matter? Stress Health. 2016;1-12.

[36] Hess U, Fischer A. Emotional mimicry in social context. Cambridge, UK: Cambridge University Press, 2014.

[37] Barsade SG. The ripple effect: Emotional contagion and its influence on group behavior. Administrative Science Quarterly. 2002;47(4):644-75.

[38] Johnson PR, Indvik J. Slings and arrows of rudeness: Incivility in the workplace. The Journal of Management Development. 2001;20:705-13.

[39] Kim H, Qu H. Employees' burnout and emotional intelligence as mediator and moderator in the negative spiral of incivility. International Journal of Contemporary Hospitality Management. 2019;31(2). Doi: 10.1108/IJCHM-122017-0794

[40] Spector PE, Fox S. The stressor-emotion model of counterproductive work behavior. In S. Fox, P.E. Spector, Eds., Counterproductive work behavior, Washington, DC: APA, 2005, pp. 151-74.

[41] Lazarus RS. Why we should think of stress as a subset of emotion. In L. Goldberger, S. Breznitz Eds., Handbook of stress: Theoretical and clinical aspects 2nd ed., New York, NY: The Free Press, 1993, pp. 21-39.

[42] Meier LL, Semmer NK. Lack of reciprocity, narcissism, anger, and instigated workplace incivility: A moderated mediation model. European Journal of Work and Organizational Psychology. 2013;22(4):461-75.

[43] Fredrickson BL, Branigan CA. Positive emotions broaden the scope of attention and thought-action repertoires. Cognition \& Emotion. 2005;19:313-32.

[44] Diong SM, Bishop GD, Enkelmann CH, Tong MW, Why YP, Ang CH, Khader M. Anger, stress, coping, social support and health: Modelling the relationships. Psychology and Health. 2005;20(4):467-95.

[45] Petitta L, Naughton S. Mapping the association of emotional contagion to leaders, colleagues, and clients: Implications for leadership. Organization Management Journal. 2015;12(3):178-92.

[46] Eurofound 2018. Burnout in the workplace: A review of data and policy responses in the EU. Retrievable at: https://www.eurofound.europa.eu/publications/report/2018 /burnout-in-the-workplace-a-review-of-data-and-policyresponses-in-the-eu.

[47] Buhrmester M, Kwang T, Gosling SD. Amazon's mechanical turk a new source of inexpensive, yet high-quality, data? Perspectives on Psychological Science. 2011;6:3-5.

[48] Brislin R. Translation and content analysis of oral and written material. In H.C. Triandis and J.W. Berry (Eds.),
Handbook of cross-cultural psychology, Boston: Allyn \& Bacon, 1980, pp. 389-444.

[49] Leiter MP. Analyzing and theorizing the dynamics of the workplace incivility crisis. New York, NY: Springer, 2013.

[50] Borgogni L, Galati D, Petitta L. Centro Formazione Schweitzer. Il questionario checkup organizzativo. Manuale dell' adattamento Italiano. [The organizational checkup questionnaire. Adapted Italian manual]. Firenze: O.S. Organizzazioni Speciali, 2005.

[51] Schaufeli WB, Leiter MP, Maslach C, Jackson SE. MBIGeneral Survey. In C. Maslach, S.E. Jackson and M.P. Leiter (Eds.), Maslach Burnout Inventory (3rd ed.). Palo Alto, CA: Consulting Psychologist Press, 1996.

[52] Little TD, Cunningham WA, Shahar G, Widaman KF. To parcel or not to parcel: Exploring the question, weighing the merits. Structural Equation Modeling: A Multidisciplinary Journal. 2002;9(2):151-73.

[53] Muthen LK, Muthen BO. Mplus Version 7 User's Guide. Los Angeles, CA: Muthen \& Muthen, 2013.

[54] Vandenberg RJ, Lance CE. A review and synthesis of the measurement invariance literature: Suggestions, practices, and recommendations for organizational research. Organizational Research Methods. 2000;3:4-69.

[55] Kamp J, Brooks P. Perceived organizational climate and employee counterproductivity. Journal of Business \& Psychology. 1991;5:447-58.

[56] Reis HT, Sprecher S. Encyclopedia of human relationships. Thousand Oaks, CA: Sage, 2009.

[57] Rosen CC, Gabriel AS, Koopman J, Johnson RE. Who strikes back? A daily investigation of when and why incivility begets incivility. Journal of Applied Psychology. 2016;101(11):1620-34.

[58] Lachman VD. Ethical issues in the disruptive behaviors of incivility, bullying, and horizontal/lateral violence. MEDSURG Nursing. 2014;23(1):56-60.

[59] Aquino K, Thau S. Workplace victimization: Aggression from the target's perspective. Annual Review of Psychology. 2009;60:717-41.

[60] American Association of Critical Care Nurses. Standards for establishing and sustaining healthy work environments: A journey to excellence. American Journal of Critical Care. 2005;14(3):187-97.

[61] Robbins SP, Judge TA. Organizational Behavior, 17th Edition. Edinburg, UK: Pearson, 2017.

[62] Bowen B, Privitera MR, Bowie V. Reducing workplace violence by creating healthy workplace environments. Journal of Aggression, Conflict and Peace Research. 2011;3:18598.

[63] Bandura A. Social Foundations of Thoughts and Actions: A Social Cognitive Theory, Prentice Hall, Englewood Cliffs, NJ, 1986.

[64] Liu X-Y, Härtel CEJ, Sun JJ-M. The workgroup emotional climate scale: Theoretical development, empirical validation, and relationship with workgroup effectiveness. Group \& Organization Management. 2014;39(6):626-63. 